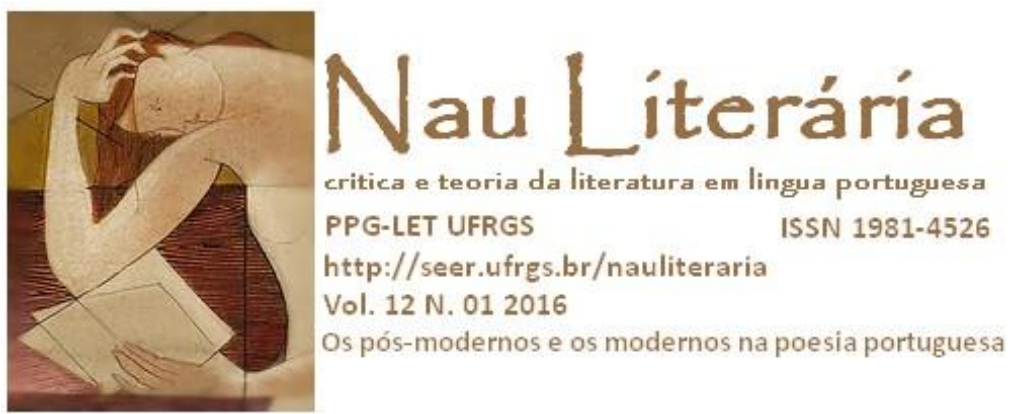

\title{
POR TRÁS DA DISTOPIA: $O$ ano de 1993, de José Saramago
}

\author{
BEHIND THE DISTHOPY: $O$ ano de 1993, by José Saramago
}

Quênia Regina Santos ${ }^{1}$

RESUMO: Este ensaio tem por objetivo analisar a obra $O$ ano de 1993, de José Saramago, que busca na narrativa poética outra maneira de fazer conhecer sua visão do mundo após golpe de estado de abril de 1974. Por trás de um tratamento metafórico marcado pelo ilogismo, o poema narrativo de Saramago mostra o sentimento de submissão de um povo diante do opressor, defendendo o amor e a união na luta como a única forma de garantir a liberdade para qualquer povo, principalmente o português, representado no longo poema, que permanecia errante, preso, longe de uma vivência democrática em seu país, estimulando-o à rebelião a fim de resgatar a possibilidade de um futuro livre.

PALAVRAS-CHAVE: Metáfora; Poder; Liberdade; Intelectual; Poesia.

ABSTRACT: This essay aims to analyze the work $O$ ano de 1993, by José Saramago, a poetic narrative that seeks another way to make known his view of the world after the coup d'état of April 1974. Thus, behind a metaphoric treatment marked by ilogism, the narrative poem by Saramago shows the feeling of submission of people who face oppressors, advocating love and union in the fight as the only way to guarantee freedom for all peoples, especially the Portuguese one, represented in the long poem, which was still wandering, imprisoned, far from a democratic experience in their country, encouraging them to rebellion in order to rescue the possibility of a free future.

KEYWORDS: Metaphor; Power; Freedom; Intellectual; Poetry.

"Ó este povo que corre nas ruas e estas bandeiras e estes gritos e estes punhos fechados".

José Saramago

\footnotetext{
1 Graduada em Letras pela Universidade do Vale do Rio dos Sinos - UNISINOS, Especialista em Literatura de Línguas Brasileira e Portuguesa, mestre e doutoranda em Literaturas Lusoafricana e Portuguesa - Universidade Federal do Rio Grande do Sul - UFRGS.
} 
Após a época das colonizações e durante os últimos anos do regime militar em Portugal, muitos do povo e da elite intelectual lutaram contra a opressão deste estado que, em 25 de abril de 1974, foi derrubado por meio de um golpe. Neste momento histórico ímpar para a sociedade portuguesa, que ainda se via com poucos direitos e oportunidades de expressão, a literatura foi uma das formas de manifestação encontrada pelos intelectuais empenhados em lutar por uma sociedade justa. Assim, muitos autores abordaram em suas obras a temática que envolve a ação dominadora da chamada Nova República que, mesmo com seu fim, continuou a deixar marcas na formação da identidade do povo português.

Dentre estes autores estava José Saramago que, como intelectual, entendia que seu papel ia além do simples fato de trazer reflexão à sociedade, pois havia também a intenção por trás dos textos, que era a de denunciar qualquer regime autoritário e manifestar sua condição de eterno defensor do socialismo. As atitudes do autor concordam com o que diz Said (2005, p. 94), pois, para ele, "uma das principais atividades do intelectual do século XX tem sido questionar, para não dizer subverter, o poder da autoridade". É certo que, nos anos após 1974, nem tudo podia ser dito claramente, e o uso de textos literários, portanto, seria uma forma de continuar o movimento antirrepressão iniciado em 1973. Assim, além de crônicas e artigos para revistas e jornais, Saramago busca na narrativa poética outra maneira de fazer conhecer sua visão do mundo daquela época.

A poesia de José Saramago mostra o grande romancista se formando. Muitos elementos que a compõem aparecerão mais tarde em seus romances, o que o possibilita afirmar que:

No fundo, não deixei de ser poeta, mas um poeta que se expressa através da prosa e provavelmente - e esta é uma ideia lisonjeira que eu quero ter em mim mesmo - é possível que eu seja hoje mais e melhor poeta do que pude ser quando escrevia poesia (SARAMAGO, 2010, p. 234).

Em $O$ ano de 1993, seu terceiro e último livro de poesias, dividido em 30 partes e publicado pela primeira vez em 1975, tanto o Saramago romancista, quanto o crítico 
movido por um viés político e social estão presentes, num poema narrativo que, através de um diagnóstico hiperbólico, traça um retrato metafórico da revolução pela qual passou o povo português na primeira metade da década de 1970. Neste sentido e lembrando-se das palavras de Said, Saramago fala sobre sua poesia e a obrigação do intelectual:

[O ano de 1993] comecei a escrevê-lo antes do 25 de Abril, precisamente no dia da tentativa militar das Caldas da Rainha. Foi por desespero que o principiei. Depois veio a Revolução, e o livro pareceu ter perdido o sentido. Se, como se dizia, o fascismo estava morto, para que falar em dominadores e dominados? Sabemos hoje que o fascismo está vivo, e eu fiz meu dever publicando o livro [em fevereiro de 75], quando ainda tínhamos vivido as horas mais belas e exaltantes da Revolução... (SARAMAGO, 2010, p. 272) ${ }^{2}$.

Suas digressões, que tanto ocorrem em seus romances, também acompanham os comentários acerca de seu modo de narrar e criar personagens, cenários e enredos que retratam situações-limite do ser humano ou marcam a história de um povo, quando também analisa sua caminhada como escritor e formador de opinião:

Minha poesia é uma poesia de segunda ou terceira classe, não vale a pena teimar. Não tive ilusões, é o que é, limpa, honesta e em algum momento terá sido algo mais do que isso, mas, enfim, não vou ficar na história como poeta. Suponho que se ficar na História será como um romancista que também fez alguns versos (SARAMAGO, 2010, p. 322).

Em $O$ ano de 1993, o texto se desenvolve fragmentadamente, por isso a leitura não pode isolar uma parte ou outra, pois o entendimento do todo é que nos remete ao mundo representado por ela metaforicamente. Neste sentido, de acordo com Ricoeur (1975, p. 323), "no nível da hermenêutica, a referência dirige-se a entidades do discurso de maior dimensão do que a frase". Ainda, para o autor, a poesia se desvia da linguagem ordinária, portanto é sempre metafórica. Desde o começo, por meio de versos semelhantes aos versículos bíblicos, o texto apresenta um cenário desolador, que traz a

2 O movimento militar de Caldas da Rainha ocorrido em 22 de fevereiro de 1974 remonta à insatisfação, entre as Forças Armadas Portuguesas, com a Guerra Colonial, a falta de liberdade política e o atraso econômico vivido pelo país e prenuncia a Revolução dos Cravos. 
ideia de falta de esperança, ou até de desistência em vez de resistência, como é observado nos seguintes versos do primeiro segmento (SARAMAGO, 2007, p. 7,8):

\section{[...] Este dia em que as pessoas estão sentadas na paisagem entre dois prumos de madeira que foram uma porta sem paredes para cima e para os lados}

Não há portanto casa nem sequer a porta que poderia não abrir precisamente por não haver para onde abrir

Apenas o vazio da porta e não a porta [...]

O fato de estas pessoas estarem sentadas mostra a situação de desânimo que as acomete, porque não sabem o que fazer e se encontram sem rumo definido, o que sugere falta de esperança quanto ao futuro. Ainda, estas pessoas, que o poema diz serem duas, conversam sobre temas cotidianos, como o tempo, mostrando que aquela situação é duradoura.

Nos seguintes versos deste poema escrito em 1975 há um intertexto com o romance A jangada de pedra, de 1986, obra na qual há uma personagem que risca o chão e, em consequência, Portugal se separa de fato do continente europeu. Já no poema, uma das duas pessoas que estavam sentadas faz também um risco no chão, o que pode representar um divisor entre o passado de opressão e um vindouro futuro livre, pois o sol que antes parecia parado já não está mais (SARAMAGO, 2007, p. 10):

Uma das pessoas vai riscando no chão uns traços enigmáticos que tanto podem ser um retrato como uma declaração de amor ou a palavra que faltasse inventar

Vê-se agora que o sol afinal não estava parado e portanto a paisagem é muito menos daliniana do que ficou dito na primeira linha 
O segundo segmento do poema mostra a doença que assola a cidade e faz com que os moradores, que não saíram dela, se reúnam na praça central, sitiados e dominados, num momento da narrativa em que o autor alude metaforicamente à angústia do povo português em ver-se impotente diante do regime de Salazar, sob o qual vive. Neste sentido, as palavras de Paul Ricoeur (1975, p. 328) ajudam a descobrir a intenção de Saramago em usar a linguagem metafórica no poema, quando ele diz que "interpretar uma obra é desvendar o mundo a que ela se refere, em virtude da sua 'disposição', do seu 'gênero', do seu 'estilo"'. O gênero de que o poeta se vale é o épico, próprio para exaltar uma história de guerra, mas num estilo afastado do modelo clássico, sem a cadência solene do metro decassílabo nem a sintaxe lógica dos eventos evocados, numa disposição entrecortada e incompleta, que figura a realidade referida como dificultosa e incompreensível.

Nos versos finais deste segmento, o cenário está assim descrito (SARAMAGO, 2007, p. 15):

Ali estão pois na praça angustiados e em silêncio à espera

E depois nada mais se ouve que uma aérea e delicada música de cravo

Qualquer fuga composta há duzentos e cinquenta anos por João Sebastião Bach em Leipzig

É então que os homens e as mulheres sem esperança se deixam cair no pavimento estalado da praça

Enquanto a música se afasta e voa sobre os campos devastados

Nestes versos, o autor sugere a esperança por trás da música numa cena em que reina o silêncio, porém, a arte, neste contexto, não é o diferencial e sim o povo, o que é evidenciado pelo afastamento da música e a permanência das pessoas no espaço em que se encontram. A fuga de Bach, este com o nome aportuguesado, poderia indicar um momento de enlevo, de vivência cultural, mas ele não permanece. 
Durante o regime de Salazar em Portugal, os mandos e desmandos do governo geraram nas pessoas um sentimento de cruel humilhação física e psicológica, em especial no caso dos condenados políticos e suas famílias. A guerra silenciosa pela qual passavam deixava marcas profundas, que se refletiam nas gerações seguintes, como heranças. Como cidadão português e intelectual de seu tempo, José Saramago estava preocupado com os possíveis caminhos para os quais o governo autoritário estava direcionando o país e seu povo, e também com as injustiças praticadas por este:

Como cidadão, todos nós temos a obrigação de intervir e de nos envolver. É o cidadão que faz as coisas mudarem. Não consigo me ver fora de nenhum tipo de envolvimento social ou político. Sim, sou escritor, mas vivo neste mundo, e minha escrita não existe em um plano separado dele (SARAMAGO, 2010, p. $354)$.

Deste modo, seu intuito ao escrever esta obra poética distópica, em que um país é assolado por uma invasão que destrói seus cidadãos com meios fabulosos e inelutáveis, concorda com a posição destacada por Said acerca da impossível separação do indivíduo do que é coletivo:

Todos nós, sem exceção, pertencemos a algum tipo de comunidade nacional, religiosa ou étnica; ninguém, por mais que seja o volume de protestos, está acima dos laços orgânicos que vinculam o indivíduo à família, à comunidade e, naturalmente, à nacionalidade (SAID, 2005, p. 53).

Desta forma, o autor busca denunciar a situação de opressão do regime salazarista e suas regras arbitrárias, o que no poema é exemplificado pela humilhação a que as mulheres são submetidas, uma vez que são violentadas e deixam-se violentar. Entretanto, antes de terminado o ato, elas cortam os membros dos homens do exército dominador que, neste contexto, novamente significa o poder, uma vez que o triângulo, ou falo, símbolo do masculino, está costurado em fardas militares. Esta ação, para elas, representa uma conquista e a resposta por tantas perseguições e mortes do lado dos dominados, assim como cada avanço que o povo conseguia contra o regime salazarista significava uma conquista para Portugal (SARAMAGO, 2007, p.34-35): 
Já tudo isto aconteceu infinitas vezes tantas que violação se não deve dizer pelo contrário entrega

Por isso a longa fileira das mulheres deitadas espera com indiferença que á simulada a penetração dos perseguidores

Elas mesmas levantaram as roupas e oferecem à luz do sol e aos olhos as vulvas húmidas

Silenciosamente suportam o assalto e abrem os braços enquanto a raiva corre pelo sangue para o centro do corpo

Há um derradeiro momento em que o perseguidor ainda poderia retirar-se

Mas logo é tarde e no exacto instante em que o espasmo militarmente iria deflagrar

Com um estalo seco e definitivo os dentes que o ódio fizera nascer nas vulvas frenéticas

Cortam cerce os pénis do exército perseguidor que as vaginas cospem para fora com o mesmo desprezo com que os homens perseguidos haviam sido degolados

A opressão sem limites ressurge na metáfora dos recenseadores, no segmento 9, quando bichos - uma cobra, um rato e uma aranha -, fazem a contagem das pessoas que estão dentro da cidade três vezes por dia para fins de controle dos invasores (p.38). Também é representada pelos homens que passam a viver como toupeiras em túneis embaixo da terra, cegamente crendo-se seguros. Há uma inversão de lugares, homens por animais, o que sugere inércia dos cidadãos portugueses dentro de seu país, ao 
sentirem-se inseguros, inferiorizados e fora do lugar, cegueira que lhes pode ser fatal (SARAMAGO, 2007, p. 38 e 40, 44):

[...]

A primeira contagem é feita pelos ratos e a segunda

pelas cobras a terceira pelas aranhas

$[\ldots]$

Todas as noites enlouquecem dois ou três habitantes da cidade

[...] Se os homens que assim escolheram viver compreendessem que têm de cavar para baixo e fundo um poço antes que venham a lança e a estaca

Para que o perseguidor morra enterrado no preciso momento em que iria matar e para que comecem a igualar-se as perdas $[\ldots]$

O início da revolução contra o exército invasor acionado pelas mulheres castradoras continua quando as crianças febris passam a sentir a mão de suas mães em seus rostos a fim de medir a temperatura, no lugar dos termômetros. Estes haviam sido requisitados pelo ocupante, cujo mercúrio era usado para formar olhos de vigilância individual que, em consequência do contato entre mãe e filho, começam a não funcionar adequadamente. $\mathrm{O}$ episódio anuncia que o poder do estado policial, dependente de recursos tecnológicos, está sendo alterado, fato que se evidencia também pelo ataque de animais, antes domésticos, aos seus donos, pertencentes ao grupo ocupante (SARAMAGO, 2007, p. 49,49):

A primeira vítima de que houve notícia foi a mulher do governador escolhido pelo ocupante

Quando o macaco amestrado que a divertia nas horas de aborrecimento a crucificou no portão do jardim enquanto as galinhas saíram da capoeira para vir arrancar-lhe à bicada as unhas dos pés

Muitas velhinhas inocentes foram arranhadas por gatos castrados de estimação em memória 
Em todas as obras do autor, a ironia é constante, mas sua presença nestes versos adquire um tom vindicativo e como recurso retórico qualifica a poesia enquanto advertência metafórica aos cidadãos coniventes com os abusos do poder. Como é sabido, havia entre os portugueses aqueles que se adaptaram resignados ao regime salazarista, assim como os que estão na cidade metafórica do poema de Saramago, que retrata em seus versos os jogos de poder que os dominadores usam para fazer com que o povo fique desunido, separado, não causando nenhuma ameaça ao governo.

$\mathrm{Na}$ parte 14, forma-se uma tribo de resistentes, sempre vigilantes, para conservar-se a salvo do inimigo. Nela dois casais dos quatro pontos cardeais ritualmente se unem, lembrando aos outros "a única canção feliz que não esqueceram”. A tribo não deixa de manter a coragem e a esperança, como se observa nestes versos, que retomam a imagem do mar, símbolo do orgulho e da grandeza de Portugal (SARAMAGO, 2007, p. 58):

Agora os homens apenas procuram o mar para se lamentarem diante da grande voz das ondas

E postos de joelhos em linha com os braços abertos recebendo no rosto a fustigação do vento e da espuma

Gritam ensurdecidos pelo estrépito a miséria extrema que por agora os dispersa na terra

E quando enfim se calam assombrados pelo pavor que são capazes de suportar

O mar subitamente acalma e um lento murmúrio de um lado e do outro reconsidera os factos

Que em verdade não excluem uma maré renovada e uma coragem à medida do tempo que passou desde a primeira vez de todas as mortes 
Sem o que não seria possível juntarem-se outra

vez os homens e subirem a escarpa a caminho

da terra ocupada

O mar, fustigando-os, faz renascer a vontade de vencer e o entusiasmo para o povo que agora se une para lutar. Neste sentido, a imagem do mar como símbolo de vitória fala ao imaginário da sociedade portuguesa que, mesmo com a dificuldade de reiniciar uma marcha para a liberdade, tem como exemplo seu passado de glórias nunca esquecido.

A esperança renovada também é representada na imagem do casal que é salvo de um ataque de feras de metal por ordem do exército dominante, por refugiarem-se dentro de uma árvore que para eles se abrira (p.78). Esta árvore, símbolo sagrado da vida, se desprende do solo, é como uma resposta da natureza ao ataque dos animais mecânicos e caminha junto com a tribo a que pertence o casal em qualquer direção.

Para o autor (SARAMAGO, 2010, P. 297), "a alegoria chega quando descrever a realidade já não serve". Assim, para reiniciar a trajetória em busca da sonhada vida em sociedade, seria necessário também reaprender a viver socialmente, o que significa restituir o poder da linguagem. É o que se prefigura pela alegoria do homem que se nota analfabeto e sente que é a mesma coisa que estar tomado pela lepra no parte 21 . A dificuldade deste reinício é comparada pelo autor com a de escrever, numa metanarrativa que deixa lacunas para a interpretação, assim como mostra o desafio de fazer poesia numa época em que a ditadura ainda tinha como interferir na vida do cidadão português, principalmente na dos que influenciavam o povo com suas opiniões (SARAMAGO, 2007, p. 86):

Talvez este silêncio seja o esforço abrindo os foles do pulmão prosaicamente abrindo ó sem poesia abrindo

Para começar o outra vez doloroso nascimento duma primeira palavra 
Outra passagem que faz um intertexto com seus romances é quando todas as mulheres do grupo que está indo em direção à cidade tomada pelos opressores se declaram grávidas, fato ocorrido em A Jangada de Pedra, quando este acontecimento também se refere à renovação da vida do povo português.

Entretanto, se a tribo prossegue, os invasores também continuam a dizimar os rebeldes com seu exército de animais-máquinas e um computador central que se alimenta de gente a comandá-los. Para que o processo de retomada da vida em sociedade vingue e, por conseguinte, a identidade individual e nacional se complete, muito sacrifício é exigido, o que nos é apresentado por Saramago pela imagem macabra e hiperbólica da ponte de mortos feitas para que os vivos por ela passarem a fim de entrar na cidade. Porém, assim que atingem seu objetivo, os sobreviventes recolhem seus mortos para resgatar o que o autor chama de "unidade primeira", que é a humanidade em cada um (SARAMAGO, 2007, p.108).

No segmento 27 da poesia narrativa, o narrador se distancia da cena após uma batalha em 1993 e julga os acontecimentos, não esquecendo que este tempo ainda não havia passado. Neste verso, futuro e presente estão juntos e representam outra alegoria, a da ditadura, que é feita por pedaços da história da humanidade (SARAMAGO, 2007, p. 108):

Distante julgaríamos o ano de 1993 e contudo é tempo dele ainda

O uso de vários verbos na primeira pessoa do plural revela a união entre os que lutaram na batalha, que só é vencida com o comprometimento de todos. Além disto, a aproximação de um bando de gaivotas configura a esperança renovada e prenuncia um destino positivo, pois eram elas que anunciavam a terra para os antigos navegadores (SARAMAGO, 2007, p. 108, 113):

Ó eloquentemente diríamos ó se não fosse preferível que percorrêssemos nós esta praia manchada de sangue dizendo algumas e discretas palavras em voz baixa meus amigos

Tanto mais que do lado do mar se aproxima 
Voando o primeiro bando de gaivotas que desde há

Muito tempo é visto nesta terra ocupada

Sinal de que talvez se reconheça enfim a vida

e de que nem tudo se perdeu nas abjecções que

consentimos algumas vezes cúmplices

Estão agora sobre nós as gaivotas pairando e

deixam pender um pouco a cabeça para melhor nos

fitarem e decidirem quem somos

Entretanto o sol saiu inteiro da madrugada en-

quanto mal feridos nos erguemos e as sentinelas

gritam a reunir porque o inimigo vem perto

Deste modo, a conquista das cidades ocupadas pelo exército ditador vai ocorrendo e a vida em sociedade volta a reinar com grande exultação por parte dos vencedores, novamente conquistadores de terras e também de sua integridade como seres humanos, livres do poder opressor. Um ar renovado toma conta dos lugares resgatados pelos homens e o arco-íris aparece todas as noites no céu como símbolo de redenção, marcando a vitória da vida sobre a escuridão da noite, que simboliza a morte (parte 29).

Nesta obra poética, o autor usa elementos como os pares de substantivos e adjetivos contrastantes, como em "gemido invisível”, ou enfáticos, como em "enorme ausência", "excesso de silêncio", ou também expressões antitéticas como "adormecidos que raramente dormem”, que valorizam a narrativa, além das anáforas que aparecem no segmento 30 com a expressão "uma vez mais" iniciando os parágrafos e indicando a persistência da retomada da liberdade.

Entretanto, o maior trunfo metafórico do texto no sentido de incitar a uma consciência dos mecanismos discricionários do regime autoritário que em 1975 ainda subjazia ao novo poder, embora desgastado, está contido em suas inúmeras alegorias, nas estranhas e inexplicáveis ocorrências com que os dominadores castigam e aniquilam o povo e nos eventos miraculosos promovidos pelo amor dos casais, das famílias, que desencadeiam a apoteose final da emancipação. 
Assim, por trás da metáfora, o poema distópico de Saramago, com seu texto livre de pontuação, fortemente fragmentado, mostra o sentimento de submissão do povo diante do opressor, mobilizando acontecimentos para além da lógica como forma de estimular movimentos em defesa da liberdade para qualquer povo, principalmente o português visado pela poesia, que permanecia preso a hábitos de conformação, longe de uma vivência democrática em seu país, reforçando a ideia de rebelião a fim de resgatar a possibilidade de um futuro livre.

\section{REFERÊNCIAS}

SAID, Edward W. Representações do intelectual: as conferências Reith de 1993. São Paulo: Companhia das Letras, 2005.

SARAMAGO, José. Palavras de Saramago. AGUILERA, Fernando Gómes (Org). São Paulo: Companhia das Letras, 2010. O ano de 1993. São Paulo: Companhia das Letras, 2007.

RICOEUR, Paul. Metáfora e referência. In: A metáfora viva. São Paulo: Loyola, 1975. 